\title{
Assessing nonresponse bias at follow-up in a large prospective cohort of relatively young and mobile military service members
}

\author{
Alyson J Littman 1,2* Edward J Boyko', Isabel G Jacobson ${ }^{3}$, Jaime Horton ${ }^{3}$, Gary D Gackstetter ${ }^{4}$, Besa Smith ${ }^{3}$, \\ Tomoko Hooper ${ }^{5}$, Timothy S Wells ${ }^{3}$, Paul J Amoroso ${ }^{6}$, Tyler C Smith ${ }^{3}$, the Millennium Cohort Study
}

\begin{abstract}
Background: Nonresponse bias in a longitudinal study could affect the magnitude and direction of measures of association. We identified sociodemographic, behavioral, military, and health-related predictors of response to the first follow-up questionnaire in a large military cohort and assessed the extent to which nonresponse biased measures of association.

Methods: Data are from the baseline and first follow-up survey of the Millennium Cohort Study. Seventy-six thousand, seven hundred and seventy-five eligible individuals completed the baseline survey and were presumed alive at the time of follow-up; of these, 54,960 (71.6\%) completed the first follow-up survey. Logistic regression models were used to calculate inverse probability weights using propensity scores.

Results: Characteristics associated with a greater probability of response included female gender, older age, higher education level, officer rank, active-duty status, and a self-reported history of military exposures. Ever smokers, those with a history of chronic alcohol consumption or a major depressive disorder, and those separated from the military at follow-up had a lower probability of response. Nonresponse to the follow-up questionnaire did not result in appreciable bias; bias was greatest in subgroups with small numbers.
\end{abstract}

Conclusions: These findings suggest that prospective analyses from this cohort are not substantially biased by non-response at the first follow-up assessment.

\section{Background}

Intragroup comparisons over time are a key strength of longitudinal cohort studies; a major threat to the validity of results from such studies is nonresponse to follow-up surveys and/or attrition, which can result in a loss of statistical power and bias. When only a subset of all participants provides follow-up information on exposures and outcomes, the participating subset may not be representative of the original sample. Prior studies have found that follow-up responders tend to differ from nonresponders in their sociodemographic and health characteristics. Since it may be difficult or impossible to determine whether nonresponse is related to the

\footnotetext{
* Correspondence: alyson@u.washington.edu

'Seattle Epidemiologic Research and Information Center, Department of Veterans Affairs Puget Sound Health Care System, Seattle, WA, USA Full list of author information is available at the end of the article
}

outcome under study, great efforts are usually devoted to maximizing participation and minimizing dropout. Despite such efforts, follow-up survey nonresponse is inevitable and the extent to which such nonresponse might bias study results is a methodological issue of high interest and ongoing concern.

Although not entirely consistent, a number of studies have found that individuals with the following characteristics are more likely to drop out of studies: men (vs. women), not married (vs. married), current smokers, lower socioeconomic status, and poorer health [1-4]. Longitudinal studies of elderly adults have noted that follow-up nonresponders are more likely to be older ([5] and references therein), while studies of younger adults have observed the opposite [2,3]. Nevertheless, few studies have investigated factors predicting nonresponse to follow-up surveys in longitudinal cohorts of younger

\footnotetext{
Fullist of author information is available at the end of the article
}

C 2010 Littman et al; licensee BioMed Central Ltd. This is an Open Access article distributed under the terms of the Creative Commons Attribution License (http://creativecommons.org/licenses/by/2.0), which permits unrestricted use, distribution, and reproduction in any medium, provided the original work is properly cited. 
adult participants. Furthermore, although bias is a major concern, most studies that have used various methods to try to account for nonresponse (e.g., inverse probability weighting and multiple imputation) have not detected substantial bias in estimated measures of association [6-10].

The Millennium Cohort is a 22-year prospective cohort study that began enrollment in 2001 and administered its first follow-up assessment in 2004. The cohort comprises a population of relatively young, highly mobile men and women, often exposed to unique and stressful job circumstances. Moreover, extensive information was collected at baseline on mental, physical, and behavioral health, in addition to sociodemographic, service-related, and occupational characteristics. Previously published Millennium Cohort studies [11-20] have included 1) an investigation of differences in early vs. late responders, 2) a comparison of the cohort to the overall military population, 3) analyses to adjust health outcomes based on the inverse of the sampling and response patterns, 4) evaluation of the early mortality experience among Millennium Cohort participants and invited non-participants, and 5) investigations of health characteristics prior to enrollment. These thorough evaluations of possible biases have demonstrated that Cohort members are generally representative of the US military, that health prior to enrollment did not influence participation, and that Cohort questionnaire data are reliable and internally consistent [11-20]. To complement these previous efforts, the objectives of the current study were to: 1) identify sociodemographic, behavioral, military, and health-related factors associated with response to the follow-up questionnaire, and 2) assess the extent to which failure to account for nonresponse may bias measures of associations between predictors and outcomes under investigation.

\section{Methods}

\section{The Millennium Cohort}

The sampling frame and participant recruitment procedures for the Millennium Cohort have been described in detail elsewhere [18]. Briefly, 256,400 military personnel, representing 11.3 percent of the 2.2 million men and women in active service as of October 1, 2000, were invited to participate in the Millennium Cohort Study between July 2001 and June 2003. Female service members, Reserve and National Guard personnel, and those previously deployed were oversampled. Enrollment was conducted by mail and later by electronic mail invitations. The e-mail invitations presented the option to complete the survey using a Web-based, online questionnaire. A total of 77,047 eligible individuals completed the baseline questionnaire; over half of the respondents did so online. Beginning in June 2004, cohort members were recontacted via e-mail and postal service to complete a follow-up survey. Twenty-nine of the responders to the baseline survey were later determined to be ineligible and 157 individuals died before June 2004. Methods for determining vital status are described in detail elsewhere [12]. Of the 76,861 individuals presumed alive at the time of the administration of the follow-up survey (June 2004-February 2006), 55,046 individuals completed it. After excluding 86 individuals with missing responses for covariates (see Statistical analyses section), 76,775 individuals were included in analyses to calculate the propensity score and 54,960 individuals were included in analyses as responders to the followup survey. All enrolled subjects provided informed consent. This study was approved by the Institutional Review Board at the Naval Health Research Center, San Diego (protocol number NHRC.2000.0007).

\section{Strategies for maximizing response}

A modified Dillman method was used to maximize participation at baseline and follow-up, and it included an introductory postcard, survey, and reminder postcard mailings, with repeated survey and reminder postcard mailings for nonresponders [21]. Semiannual e-mails and postcards (sent on Memorial Day and Veterans Day) were used to track participants, sustain interest in continued participation, and verify accuracy of contact information [22]. Participants were sent specially designed messages thanking them for their contribution to military service and to the study and directing them to the study Web site to obtain information on study progress and findings and to update their contact information. In addition, the US Postal Service's "Return Service Requested" was used to obtain forwarding addresses on undeliverable postcards.

\section{Data collection}

Demographic and military data were obtained from the electronic personnel files of the Defense Manpower Data Center and included gender; birth date; race/ethnicity; education; marital status; branch of service; service component; military pay grade; military occupation; deployment experience to Southwest Asia, Bosnia, or Kosovo between 1998 and 2000; deployment experience in support of the wars in Iraq and Afghanistan between 2001 and 2006; and military status at follow-up.

Self-reported data on diagnosed medical conditions, symptoms, psychosocial assessment, occupation(s), use of alcohol and tobacco, as well as military-specific and occupational exposures were obtained from the Millennium Cohort baseline questionnaire, which consisted of more than 450 questions. More information about the survey instrument is available elsewhere [18]. 


\section{Statistical analyses}

To assess differences in terms of demographic, deployment, occupational, and behavioral characteristics between responders and nonresponders to the follow-up questionnaire, we first conducted descriptive analyses using chi-square tests of association. Next, to calculate propensity scores, we conducted multivariable logistic regression with response to the follow-up questionnaire as the outcome variable. In this case, the propensity score can be thought of as the conditional probability that a person responds given the set of covariates. We assumed that data were missing at random (MAR), meaning that the probability of nonresponse at followup depended only on observed data. We used the likelihood ratio test to compare models including a given variable versus absence of the variable in the model (the nested model). Variables with $P$ values $>0.05$ were removed from the model. We considered for inclusion all variables included in Table 1 as well as the following variables: deployment to Southwest Asia, Bosnia, or Kosovo between 1998 and 2000; binge drinking (drinking $\geq 5$ drinks on a single occasion); survey mode (paper vs. Web); body mass index category $(<18.5,18.5-24.9$, 25.0-29.9, $\geq 30 \mathrm{~kg} / \mathrm{m}^{2}$ ); and panic syndrome, other anxiety, eating disorder, hypertension, diabetes, chronic fatigue syndrome, and posttraumatic stress disorder (PTSD), which were all coded as yes/no responses. The final model was comprised of the variables presented in Table 1. To assess the robustness of our model inclusion criterion, we also compared nested models using Akaike's Information Criterion (AIC). The AIC is a calculated index that takes into account both the statistical goodness of fit and the number of parameters that have to be estimated to achieve this particular degree of fit by imposing a penalty for increasing the number of parameters. Lower values of the index indicate the preferred model, that is, the one with the fewest number of parameters that still provides an adequate fit to the data. The same factors were retained in our model whether we determined inclusion based on a $P$ value $<0.05$ or a lower AIC.

To improve the predictive value of our model, we considered the following first-order interaction terms for inclusion based on a review of the scientific literature and the strength of associations in the multivariable analyses (previous step): gender, age, education, and race/ethnicity, each with the others and with each of the following: marital status, military pay grade, military status at follow-up, service branch, and self-reported health status. We also considered interactions between age and deployment experience and age and self-reported military exposures. We used a two-step process to determine which interaction terms to include in the final model. First, we added interaction terms to the main effects model one at a time. The terms with a $P$ value $>$ 0.05 were dropped from further consideration. In the second step, we sequentially added the interaction terms with the smallest $P$ value (or smallest AIC in cases of the same $P$ value) from the first step. Interaction terms with $P>0.05$ after inclusion of main effects and the other interaction terms were subsequently removed from the model.

We used the inverse of the propensity score calculated from the multivariable logistic regression model described above to calculate a probability weight for each person, although only responders to the follow-up questionnaire were included in subsequent analyses [23]. Individuals with lower propensities for response were weighted more heavily than those with higher propensities, such that a responder with a propensity equal to 0.2 carried a weight of 5 and a responder with a propensity equal to 0.85 carried a weight of 1.18 . The sum of the assigned weights is equal to the baseline population $(\mathrm{n}=76,775)$.

To evaluate the extent to which nonresponse may have influenced measures of association, we used logistic regression along with survey commands that allowed for weighting responders according to their propensity score-derived weights ("weighting for nonresponse"). We selected three outcomes that had been previously studied using Millennium Cohort Study data: disordered eating, depression, and PTSD [24-26]. These outcomes were chosen to include a range of important physical and mental health outcomes. We used the same exclusion criteria and adjusted for the same factors as in the original published studies in order to compare nonresponse-weighted results with the published findings [24-26]. Additionally, to evaluate whether weighting for nonresponse affected estimates of self-reported health at follow-up, we conducted a fourth analysis with selfreported health (five-level variable: excellent, very good, good, fair, poor) as the outcome. For this analysis, we adjusted the proportions based on the propensity scorederived weights.

\section{Results}

Table 1 shows the distribution of demographic and military characteristics ascertained from the DMDC; selfreported military, behavioral, and health characteristics; and survey response characteristics among responders and nonresponders. Overall, 71.6 percent $(n=54,960)$ of individuals completed the first follow-up survey. The response proportion was 10 or more percentage points above average (i.e., $\geq 81.6$ percent) in the following subgroups: age $\geq 44$ years, educational level of a bachelor's degree or higher; and rank of warrant or commissioned officer. The response proportion was 10 or more percentage points below average ( $\leq 61.6$ percent) among 
Table 1 Characteristics of Millennium Cohort Study participants according to response to follow-up and multivariable regression coefficients predicting response $(N=76,775)$

\begin{tabular}{|c|c|c|c|c|c|c|}
\hline \multirow[t]{3}{*}{ Characteristic } & \multicolumn{4}{|c|}{ Follow-up response status } & \multicolumn{2}{|c|}{$\begin{array}{l}\text { Multivariable logistic } \\
\text { regression model }\end{array}$} \\
\hline & \multicolumn{2}{|c|}{$\begin{array}{l}\text { Follow-up } \\
\text { responder } \\
N=54,960\end{array}$} & \multicolumn{2}{|c|}{$\begin{array}{c}\text { Follow-up } \\
\text { nonresponder } \\
N=21,815\end{array}$} & \multirow[t]{2}{*}{$\begin{array}{l}\text { Beta (standard } \\
\quad \text { error) }\end{array}$} & \multirow[t]{2}{*}{$\begin{array}{c}P \\
\text { value }\end{array}$} \\
\hline & $n$ & $\%$ & $n$ & $\%$ & & \\
\hline Intercept & & & & & $-0.24(0.07)$ & 0.0006 \\
\hline \multicolumn{7}{|c|}{$\begin{array}{l}\text { Demographic and military characteristics obtained from the Defense Manpower } \\
\text { Data Center }\end{array}$} \\
\hline \multicolumn{7}{|c|}{ Gender } \\
\hline Male & 40,311 & 71.7 & 15,895 & 28.3 & Ref & $<0.0001$ \\
\hline Female & 14,649 & 71.2 & 5,920 & 28.8 & $0.36(0.07)$ & \\
\hline \multicolumn{7}{|l|}{ Age group (years) } \\
\hline $17-24$ & 7,932 & 54.7 & 6,576 & 45.3 & Ref & $<0.0001$ \\
\hline $25-34$ & 19,249 & 71.3 & 7,766 & 28.7 & $0.56(0.08)$ & \\
\hline $35-44$ & 19,600 & 77.4 & 5,727 & 22.6 & $1.03(0.09)$ & \\
\hline$>44$ & 8,179 & 82.4 & 1,746 & 17.6 & $1.26(0.12)$ & \\
\hline \multicolumn{7}{|l|}{ Race/ethnicity } \\
\hline White, non-Hispanic & 38,965 & 72.9 & 14,468 & 27.1 & Ref & $<0.0001$ \\
\hline Black, non-Hispanic & 6,721 & 63.5 & 3,859 & 36.5 & $-0.49(0.03)$ & \\
\hline Asian/Pacific Islander & 4,859 & 80.1 & 1,207 & 19.9 & $-0.02(0.05)$ & \\
\hline Native American & 453 & 66.8 & 225 & 33.2 & $-0.10(0.14)$ & \\
\hline Hispanic & 3,202 & 64.9 & 1,728 & 35.1 & $-0.30(0.05)$ & \\
\hline Other & 760 & 69.9 & 328 & 30.1 & $-0.19(0.09)$ & \\
\hline \multicolumn{7}{|l|}{ Education } \\
\hline Less than high school & 2,957 & 62.9 & 1,743 & 37.1 & Ref & $<0.0001$ \\
\hline High school diploma or equivalent & 21,053 & 64.1 & 11,802 & 35.9 & $0.28(0.07)$ & \\
\hline Some college & 14,593 & 74.4 & 5,011 & 25.6 & $0.66(0.08)$ & \\
\hline Bachelor's degree & 10,353 & 81.7 & 2,312 & 18.3 & $0.76(0.16)$ & \\
\hline Postgraduate & 6,004 & 86.4 & 947 & 13.6 & $2.37(1.07)$ & \\
\hline \multicolumn{7}{|l|}{ Marital status } \\
\hline Never married & 14,548 & 63.0 & 8,541 & 37.0 & Ref & $<0.0001$ \\
\hline Married & 36,484 & 75.3 & 11,949 & 24.7 & $0.10(0.02)$ & \\
\hline Divorced/widowed/separated & 3,928 & 74.8 & 1,325 & 25.2 & $0.04(0.04)$ & \\
\hline \multicolumn{7}{|l|}{ Branch of service } \\
\hline Army & 26,261 & 72.2 & 10,118 & 27.8 & Ref & $<0.0001$ \\
\hline Navy/Coast Guard & 9,918 & 70.0 & 4,259 & 30.0 & $-0.20(0.03)$ & \\
\hline Marines & 2,257 & 57.6 & 1,659 & 42.4 & $-0.43(0.05)$ & \\
\hline Air Force & 16,524 & 74.1 & 5,782 & 25.9 & $-0.24(0.03)$ & \\
\hline \multicolumn{7}{|l|}{ Service component } \\
\hline Reserve/Guard & 24,084 & 73.0 & 8,928 & 27.0 & Ref & $<0.0001$ \\
\hline Active duty & 30,876 & 70.6 & 12,887 & 29.4 & $0.44(0.02)$ & \\
\hline \multicolumn{7}{|l|}{ Military pay grade } \\
\hline Enlisted & 40,089 & 67.8 & 19,046 & 32.2 & Ref & 0.0005 \\
\hline Warrant officer & 1,168 & 84.5 & 214 & 15.5 & $0.23(0.10)$ & \\
\hline Commissioned officer & 13,703 & 84.3 & 2,555 & 15.7 & $0.20(0.07)$ & \\
\hline \multicolumn{7}{|l|}{ Occupational category } \\
\hline Combat specialists & 11,212 & 73.0 & 4,153 & 27.0 & Ref & $<0.0001$ \\
\hline Electronic equipment repair & 5,050 & 74.6 & 1,717 & 25.4 & $0.21(0.04)$ & \\
\hline Communications/intelligence & 3,894 & 71.9 & 1,523 & 28.1 & $0.16(0.04)$ & \\
\hline Health care & 6,144 & 77.0 & 1,837 & 23.0 & $0.14(0.04)$ & \\
\hline Other technical and allied specialists & 1,379 & 70.0 & 590 & 30.0 & $0.08(0.06)$ & \\
\hline
\end{tabular}


Table 1 Characteristics of Millennium Cohort Study participants according to response to follow-up and multivariable regression coefficients predicting response $(N=76,775)$ (Continued)

\author{
Craft workers \\ Service and supply \\ Students, trainees, and other \\ None \\ Deployed \\ Military status at follow-up \\ Enlisted \\ Officer \\ No longer in military, retired \\ No longer in military, other
}

Functional support and administration

Electrical/mechanical equipment repair

Deployment experience between 2001 and 2006

Self-reported military, behavioral, and health characteristics

Self-reported military exposures

No reported exposures

Witnessed a person's death due to war, disaster, or tragic event

Chemical or biological warfare agents

Both

Chronic drinking

No

Yes

Smoking status

Nonsmoker

Ever/past smoker

Current smoker

Unknown

Self-reported general health
Excellent
Very good
Good
Fair
Poor
Unknown

Major depressive disorder

No

Yes

Survey response characteristics

Early response to baseline questionnaire ${ }^{b}$

No

Yes

$37,656 \quad 68.9 \quad 17,019 \quad 31.1$

$\begin{array}{llll}17,304 & 78.3 & 4,796 & 21.7\end{array}$

$\begin{array}{llll}40,823 & 70.8 & 16,799 & 29.2\end{array}$

$\begin{array}{llll}34,324 & 71.7 & 13,560 \quad 28.3\end{array}$

$\begin{array}{llll}14,727 & 84.5 & 2,706 & 15.5\end{array}$

$2,120 \quad 38.6 \quad 3,373 \quad 61.4$

$$
\begin{aligned}
& 39 \\
& 12 \\
& 1, \\
& 1,
\end{aligned}
$$$$
\begin{array}{llll}
32,102 & 74.0 & 11,287 & 26.0
\end{array}
$$$$
\begin{array}{llll}
8,332 & 64.7 & 4,538 & 35.3
\end{array}
$$$$
\begin{array}{llll}
932 & 50.4 & 919 & 49.6
\end{array}
$$

$\begin{array}{llll}11,248 & 75.0 & 3,746 & 25.0\end{array}$

$\begin{array}{llll}53,431 & 72.0 & 20,818 \quad 28.0\end{array}$

$0.11(0.03)$

$0.05(0.03)$

$0.08(0.05)$

$0.06(0.04)$

$0.02(0.04)$

Ref

$0.08(0.02)$

Ref

$0.76(0.18)$

$-1.51(1.24)$

$-1.03(0.15)$$$
\begin{array}{ccccc}
39,197 & 70.9 & 16,074 & 29.1 & \text { Ref } \\
12,708 & 73.2 & 4,652 & 26.8 & 0.05(0.02) \\
1,427 & 72.6 & 538 & 27.4 & 0.12(0.06) \\
1,628 & 74.7 & 551 & 25.3 & 0.09(0.05)
\end{array}
$$$$
\begin{array}{lllll}
51,186 & 72.1 & 19,811 & 27.9 & \text { Ref }
\end{array}
$$$$
-0.07(0.03)
$$$$
\text { Ref }
$$$$
-0.06 \text { (0.02) }
$$$$
-0.22(0.02)
$$$$
-0.22(0.02)
$$$$
-0.97(0.05)
$$

$$
\text { Ref }
$$

$0.06(0.02)$

$0.04(0.03)$

$0.02(0.04)$

$-0.14(0.10)$

$-0.24(0.05)$

Ref

0.0010

$-0.16(0.05)$

0.0192

$$
<0.0001
$$

$<0.0001$

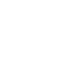

0.01

.


individuals who were aged 17-24 years, no longer in the military at follow-up for reasons other than retirement, Marine Corps service members, missing smoking status, and those who reported having poor health or a major depressive disorder.

Table 1 also includes the adjusted beta coefficients and $P$ values for the full propensity score model for each stratum compared with its reference category. A coefficient $<0$ indicates that the multivariable-adjusted probability of response is smaller than the reference category (equivalent to an odds ratio $[\mathrm{OR}]<1$ ). Conversely, coefficients $>0$ indicate that the multivariable adjusted probability of response is larger than the reference category (equivalent to $\mathrm{OR}>1$ ). To describe an individual's estimated multivariable response probability, beta coefficients across the various characteristics are summed. Since the focus of this analysis was on development of the propensity scores, and not specific ORs, coefficients for each interaction term are not shown in Table 1; the following example is provided for illustration. Women in the Army with less than a high school education (the reference category) were more likely to respond than men in the Army with less than a high school education $(\mathrm{OR}=\exp [0.36]=1.43)$. In contrast, women in the Army with a bachelor's degree were no more likely to respond than men in the Army with the same level of education $(\mathrm{OR}=\exp [0.36+(-0.33)]=$ 1.03).

Figure 1 presents information about the distribution of propensity scores. The mean propensity score was 0.75 , indicating that the average weight given to each followup responder was 1.33 , while the minimum and maximum weights were 1.03 and 14.4, (corresponding to maximum and minimum propensity scores of 0.97 and 0.0696 , respectively). The $C$ statistic, a measure of the goodness of fit for the model, was equal to 0.71 .

Tables 2, 3, and 4 present ORs and 95 percent confidence intervals (CIs) for the complete case analysis (i.e., "unweighted" results, ignoring nonresponse) and weighted for nonresponse for the association between new-onset eating disorders (Table 2), depression (Table 3 ), and PTSD (Table 4), respectively, and various exposures, including deployment experience, history of alcohol misuse, and smoking status. In the unweighted

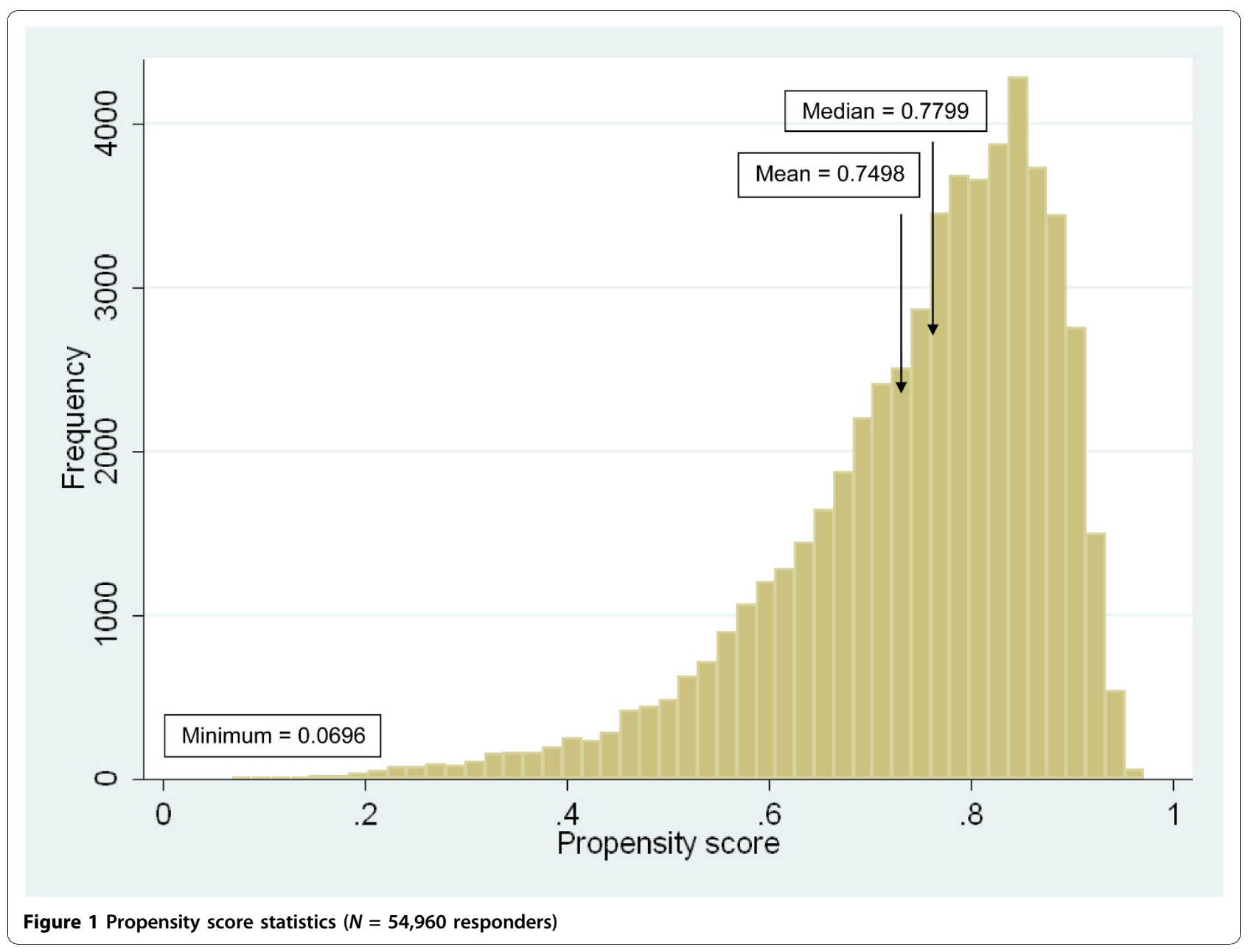


analyses, the following characteristics were associated with increased risks of new-onset eating disorders (Table 2): a history of diagnosed mental disorders (men and women), being on a special diet for weight loss (men and women), being active duty (vs. Reserve/Guard, men only), and a history of major life stressors or alcohol misuse (both for men only). After weighting for nonresponse, there was little change in ORs for any strata and no change in the interpretation of results. In some cases, the 95 percent CIs were slightly wider for the nonresponse-weighted estimates. Associations between new-onset depression and deployment experience, smoking status, problem drinking, and PTSD at baseline among men and women were similar with and without weighting for nonresponse (Table 3), although 95 percent CIs were again slightly wider in some cases after weighting for nonresponse.

As in the published study by Smith et al. [26], ORs for the associations of deployment experience, gender, smoking status, problem drinking, military rank, and new-onset PTSD were stratified by service branch (Army, Air Force, Navy and Coast Guard, and Marines; Table 4). The number of new-onset PTSD cases by service branch was 906 for Army, 184 for Air Force, 195 for Navy and Coast Guard, and 62 for Marine Corps. Particularly for Marines, the sample sizes were small and resulted in relatively imprecise OR estimates. In Army, Navy, and Coast Guard members, deployment without combat exposures was associated with statistically significant reductions in new-onset PTSD in the nonresponse weighted analyses, but not in the complete case analyses (nonresponse weighted analyses: Army, OR: 0.63, 95 percent CI: 0.44, 0.92; Navy/Coast Guard, OR: $0.48,95$ percent CI: $0.25,0.90$ ). Weighting for nonresponse in analyses of Marines resulted in a shift in ORs from greater than one to less than one, but the 95 percent CIs for both the unweighted and weighted analyses included the null value. For all service branches, the associations between deployment with combat exposure and risk of new-onset PTSD remained strong and positive after weighting. In the unweighted analyses, problem drinking in Marines was associated with a 73 percent increased risk of PTSD, which was of borderline statistical significance $(\mathrm{OR}=1.73,95$ percent $\mathrm{CI}: 1.00$, 2.99); after weighting for nonresponse, the point estimate was attenuated toward the null and the confidence

Table 2 Comparison of associations of new-onset eating disorders based on complete case results (ignoring nonresponse) and weighted for nonresponse

\begin{tabular}{|c|c|c|c|c|}
\hline & \multicolumn{4}{|c|}{ Adjusted odds ratio $(95 \% \mathrm{Cl})$ of new-onset eating disorders } \\
\hline & \multicolumn{2}{|c|}{ Women $(N=12,641)$} & \multicolumn{2}{|c|}{ Men $(N=33,577)$} \\
\hline & $\begin{array}{l}\text { Complete case } \\
\text { analysis }\end{array}$ & $\begin{array}{l}\text { Weighted for } \\
\text { nonresponse }\end{array}$ & $\begin{array}{l}\text { Complete case } \\
\text { analysis }\end{array}$ & $\begin{array}{l}\text { Weighted for } \\
\text { nonresponse }\end{array}$ \\
\hline \multicolumn{5}{|l|}{ Deployment experience } \\
\hline Nondeployed & 1.00 & 1.00 & 1.00 & 1.00 \\
\hline $\begin{array}{l}\text { Deployed without combat } \\
\text { exposures }\end{array}$ & $0.83(0.56,1.23)$ & $0.89(0.60,1.32)$ & $0.91(0.73,1.13)$ & $0.90(0.72,1.13$ \\
\hline Deployed with combat exposures & $1.29(0.91,1.85)$ & $1.33(0.93,1.90)$ & $0.94(0.77,1.15)$ & $0.96(0.77,1.18$ \\
\hline \multicolumn{5}{|l|}{ Service component } \\
\hline Reserve/Guard & 1.00 & 1.00 & 1.00 & 1.00 \\
\hline Active duty & $1.19(0.95,1.48)$ & $1.20(0.96,1.50)$ & $1.28(1.10,1.49)$ & $1.35(1.14,1.60$ \\
\hline \multicolumn{5}{|l|}{ Life stressor scale category } \\
\hline Low/mild & 1.00 & 1.00 & 1.00 & 1.00 \\
\hline Moderate & $1.12(0.89,1.43)$ & $1.18(0.92,1.52)$ & $1.15(0.92,1.44)$ & $1.15(0.90,1.46$ \\
\hline Major & $1.24(0.84,1.82)$ & $1.20(0.81,1.77)$ & $1.75(1.18,2.57)$ & $1.77(1.17,2.68$ \\
\hline \multicolumn{5}{|l|}{$\begin{array}{l}\text { History of diagnosed mental } \\
\text { disorder }\end{array}$} \\
\hline No & 1.00 & 1.00 & 1.00 & 1.00 \\
\hline Yes & $1.83(1.45,2.32)$ & $1.79(1.40,2.30)$ & $1.88(1.51,2.34)$ & $2.07(1.61,2.67$ \\
\hline \multicolumn{5}{|l|}{ History of alcohol misuse } \\
\hline No & 1.00 & 1.00 & 1.00 & 1.00 \\
\hline Yes & $1.29(0.99,1.68)$ & $1.27(0.96,1.68)$ & $1.44(1.24,1.67)$ & $1.52(1.29,1.79$ \\
\hline \multicolumn{5}{|l|}{ Special diet for weight loss } \\
\hline No & 1.00 & 1.00 & 1.00 & 1.00 \\
\hline Yes (Diet) & $2.26(1.84,2.78)$ & $2.27(1.82,2.82)$ & $2.54(2.15,2.99)$ & $2.42(2.04,2.88$ \\
\hline
\end{tabular}

Abbreviations: $\mathrm{Cl}$, confidence interval

Details on exclusion criteria and adjustment factors have been published elsewhere [13]. 
Table 3 Comparison of associations of new-onset depression based on complete case results (ignoring nonresponse) and weighted for nonresponse

\begin{tabular}{|c|c|c|c|c|}
\hline & \multicolumn{4}{|c|}{ Adjusted odds ratio $(95 \% \mathrm{Cl})$ of new-onset depression } \\
\hline & \multicolumn{2}{|c|}{ Women $(N=10,178)$} & \multicolumn{2}{|c|}{ Men $(N=30,041)$} \\
\hline & $\begin{array}{l}\text { Complete case } \\
\text { analysis }\end{array}$ & $\begin{array}{l}\text { Weighted for non- } \\
\text { response }\end{array}$ & $\begin{array}{l}\text { Complete case } \\
\text { analysis }\end{array}$ & $\begin{array}{l}\text { Weighted for non- } \\
\text { response }\end{array}$ \\
\hline \multicolumn{5}{|l|}{ Deployment experience } \\
\hline Nondeployed & 1.00 & 1.00 & 1.00 & 1.00 \\
\hline $\begin{array}{l}\text { Deployed without combat } \\
\text { exposures }\end{array}$ & $0.65(0.47,0.89)$ & $0.61(0.44,0.84)$ & $0.66(0.53,0.83)$ & $0.65(0.52,0.83)$ \\
\hline Deployed with combat exposures & $2.13(1.70,2.65)$ & $1.99(1.58,2.50)$ & $1.32(1.13,1.54)$ & $1.31(1.12,1.55)$ \\
\hline \multicolumn{5}{|l|}{ Smoking status } \\
\hline Never smoker & 1.00 & 1.00 & 1.00 & 1.00 \\
\hline Past smoker & $1.30(1.09,1.55)$ & $1.34(1.11,1.62)$ & $1.18(1.02,1.36)$ & $1.23(1.06,1.43)$ \\
\hline Current smoker & $1.35(1.10,1.66)$ & $1.42(1.14,1.78)$ & $1.52(1.31,1.77)$ & $1.57(1.33,1.85)$ \\
\hline \multicolumn{5}{|l|}{ Problem drinking } \\
\hline No & 1.00 & 1.00 & 1.00 & 1.00 \\
\hline Yes & $1.27(1.03,1.57)$ & $1.31(1.04,1.63)$ & $1.19(1.04,1.37)$ & $1.23(1.06,1.43)$ \\
\hline \multicolumn{5}{|l|}{ Posttraumatic stress at baseline } \\
\hline No & 1.00 & 1.00 & 1.00 & 1.00 \\
\hline Yes & $2.98(2.07,4.28)$ & $3.04(2.09,4.43)$ & $4.29(3.34,5.50)$ & $3.91(2.98,5.13)$ \\
\hline
\end{tabular}

Abbreviations: $\mathrm{Cl}$, confidence interval

Details on exclusion criteria and adjustment factors have been published elsewhere [25].

limits widened to include 1.0 (OR: 1.60, 95 percent CI: $0.84,3.04)$. Similarly, the association between enlisted rank and new-onset PTSD among Navy and Coast Guard members was no longer statistically significant (unweighted OR: 2.14, 95 percent CI: 1.16, 3.94; weighted for nonresponse OR: 1.99, 95 percent CI: 0.85, 1.68). Nevertheless, in both cases, the point estimates did not change substantially.

There was little difference in the distribution of selfreported health at follow-up, with and without weighting for nonresponse (data not shown). Adjusting for nonresponse resulted in a slightly greater proportion of individuals classified as having poor (0.9 percent weighted for nonresponse vs. 0.8 percent unweighted), fair (8.7 percent weighted for nonresponse vs. 8.1 percent unweighted), and good (35.4 percent weighted for nonresponse vs. 34.5 percent unweighted) health, and a smaller proportion classified as reporting very good (38.4 percent weighted for nonresponse vs. 39.2 percent unweighted) or excellent heath (15.3 percent weighted for nonresponse vs. 16.1 percent unweighted).

\section{Discussion}

Using baseline and follow-up data from the Millennium Cohort Study, we evaluated nonresponse bias in a large, relatively young, mobile population of military personnel. A large number of factors were independently associated with response to the follow-up questionnaire. The characteristics associated with a greater probability of response included female gender, increasing age, higher education level, ever married, officer rank, active duty, and self-reported history of military exposures prior to 2001 (vs. none). Ever smokers, those with a history of chronic alcohol consumption or a major depressive disorder at baseline, and those who separated from the military at follow-up, either for retirement or other reason, had a lower probability of response to the followup questionnaire. There was no difference in response by history of PTSD, panic disorder, or mode of response (i.e., paper vs. Web) and, thus, these characteristics were not included in Table 1 or subsequent models. Not surprisingly, many of the factors associated with response to the follow-up questionnaire were the same ones associated with response to the baseline questionnaire, namely female gender, older age, non-Hispanic White or Asian/Pacific Islander race/ethnicity, higher education level, ever being married, in the Army or Air Force, warrant or commissioned officer, and from health care or functional support and administration occupations (See Additional File 1) [18]. Many of these characteristics (e.g., female gender, older age, and higher education level) have commonly been associated with greater levels of response [27-29].

The use of propensity scores and weighting for nonresponse allowed us to determine if previous estimates made using complete case analysis were affected by nonresponse. Our results indicated that nonresponse did not substantially affect our estimates of health outcomes related to deployment or other risk factors. Moreover, the self-reported general health of cohort members at 
Table 4 Comparison of associations of new-onset posttraumatic stress disorder based on complete case results (ignoring nonresponse) and weighted for nonresponse

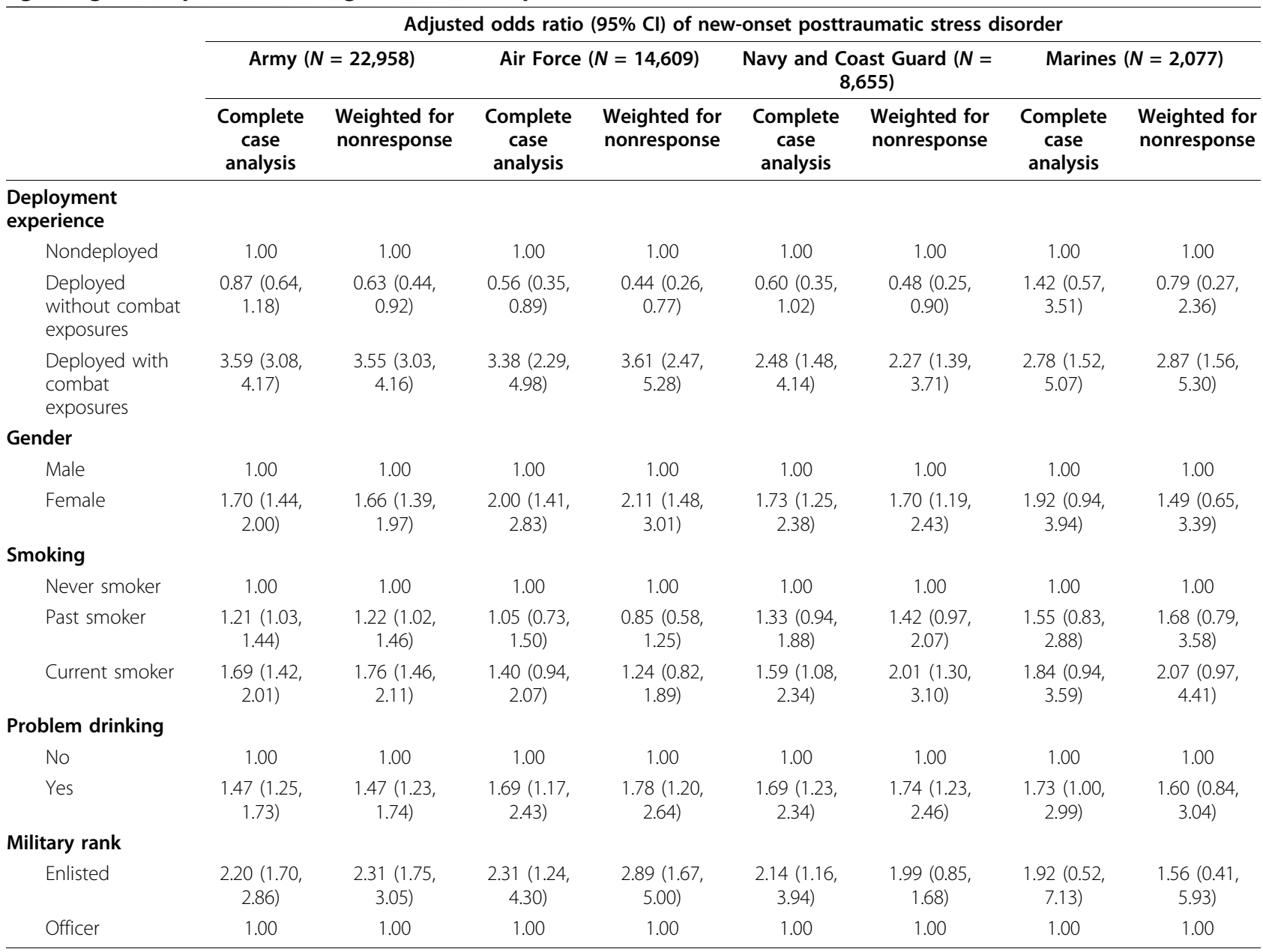

Abbreviations: $\mathrm{Cl}$, confidence interval

Details on exclusion criteria and adjustment factors have been published elsewhere [26].

follow-up did not appear to be different after weighting for nonresponse. Only where the precision of estimates was low (e.g., new-onset PTSD among Marines) was there a meaningful change in the point estimates that would affect interpretation. Nevertheless, even in this example, since the results from both the unweighted and the weighted analyses were imprecise, it would be imprudent to draw specific conclusions using either method.

There are several limitations that should be considered when interpreting our results. First, since we were unable to collect self-reported follow-up data on nonresponders, we weighted responses/outcomes among responders based on a large number of characteristics to reflect responses of nonresponders at follow-up. Also, we assumed that the data were MAR and if this assumption was invalid, we may not have been successful in adjusting for nonresponse. However, the fact that so much data were collected at baseline reduces the likelihood that some unmeasured factors that are associated with nonresponse were not captured [23]. Second, we were unable to determine whether people did not respond due to refusal (i.e., they received the questionnaire, but chose not to complete it) or inability to be contacted (e.g., the questionnaire was never received due to a change in address, deployment or occupational situation prevented contact via postal or electronic mail, or blocked e-mails). With such a high rate of operational tempo over the past decade, maintaining contact with military personnel who deploy frequently and for sometimes lengthy periods of time or who are required to move and backfill positions around the country has been a challenge. It is plausible that frequent residential moves (typical of the current military lifestyle) may be unrelated to health outcomes. Nevertheless, we were unable to determine whether nonresponse was associated with outcomes under study and 
potentially incompatible with the MAR assumption. To obtain a better understanding of the possible reasons for nonresponse and characteristics of nonresponders, in 2005 , a study of 3,000 nonresponders was conducted (RTI International, unpublished manuscript). Ultimately, 30 percent $(n=908)$ of the nonresponders were contacted and agreed to answer questions. Self-reported health status appeared to differ somewhat between responders to the ancillary study (but nonresponders to the survey in the current study) and responders. Ancillary study responders ("nonresponders") were more likely to report excellent ( 25 percent vs. 16 percent weighted for survey nonresponse) and fair (10 percent vs. 8 percent weighted for survey nonresponse) or poor (2.1 percent vs. 0.8 percent weighted for survey nonresponse) health compared with responders. However, these data are difficult to interpret since those agreeing to participate in the ancillary study are not likely to be a representative, random sample of all study nonresponders, and instead may represent a subset of individuals who were too busy (reflected in the greater proportion reporting excellent health) or too sick (reflected in the greater proportion reporting poor health) to respond to the initial survey. A third potential limitation was our ability to adequately model response. If response was not adequately modeled, our ability to adjust for nonresponse would be diminished. However, this seems unlikely since to create the propensity score, we evaluated a large number of characteristics among baseline responders, including demographic, military, behavioral, and medical characteristics and the $\mathrm{C}$ statistic of 0.71 indicated a good fit of the model.

\section{Conclusions}

In summary, we found that in this relatively young adult, highly mobile cohort, several factors previously identified (e.g., male gender, younger age, lower education), as well as some novel factors (e.g., separation from the military), were associated with lower probability of response. To reduce nonresponse in future followup surveys, it will be important to put additional efforts into maintaining contact and encouraging participation for individuals with these characteristics. Furthermore, because individuals who separate from the military (or analogously for an occupational cohort, individuals who are no longer working in the industry) may incorrectly assume that they are no longer enrolled in the study, it will be helpful to continue to employ strategies for the future follow-up cycles that proactively inform these individuals regarding the importance of their continued participation, regardless of their current occupational status. In this study population, nonresponse to the follow-up questionnaire did not result in appreciable bias as reflected by comparing measures of association for selected outcomes using complete case and inverse probability weighted methods. The potential for bias seemed greatest in subsamples with smaller numbers, as there were slight differences in point estimates and precision obtained from these two methods of analysis. Nevertheless, there is no substitute for adequate followup to support proper epidemiologic inference; efforts to achieve and maintain high response rates are a worthwhile investment in this, and all prospective cohort studies.

\section{Additional material}

Additional file 1: Distribution of various demographic and military characteristics in the sample invited to participate in the Millennium Cohort Study in 2001 and responders to the first follow-up survey in 2004.

\section{Abbreviations}

AIC: Akaike's Information Criterion; Cl: confidence interval; MAR, missing at random; OR: odds ratio; PTSD: posttraumatic stress disorder

\section{Acknowledgements}

This material is based upon work supported in part by the U.S. Department of Veterans Affairs, Office of Research and Development, Cooperative Studies Program. This work represents report 09.34, supported by the Department of Defense, under work unit no. 60002. The views expressed in this article are those of the authors and do not necessarily reflect the position or policy of the Department of Veterans Affairs, Department of the Navy, Department of the Army, Department of the Air Force, Department of Defense, or the US Government. This research has been conducted in compliance with all applicable federal regulations governing the protection of human subjects in research (Protocol NHRC.2000.007).

We are indebted to the Millennium Cohort Study participants, without whom these analyses would not be possible. In addition to the authors, the Millennium Cohort Study Team includes Gregory C. Gray, MD, MPH, from the College of Public Health, University of lowa, lowa City, IA; James R. Riddle, DVM, MPH, from the Air Force Research Laboratory, Wright-Patterson Air Force Base, OH; Margaret A. K. Ryan, MD, MPH, from Naval Hospital Camp Pendleton, Occupational Health Department; Melissa Bagnell, MPH; Lacy Farnell; Gia Gumbs, MPH; Nisara Granado, MPH, PhD; Kelly Jones; Cynthia LeardMann, MPH; Travis Leleu; Jamie McGrew; Amanda Pietrucha, MPH; Teresa Powell, MS; Donald Sandweiss, MD; Amber Seelig, MPH; Katherine Snell; Steven Speigle; Kari Welch, MA; Martin White, MPH; James Whitmer; and Charlene Wong, MPH; from the Department of Deployment Health Research, Naval Health Research Center, San Diego, CA. We thank Scott L. Seggerman and Greg D. Boyd from the Management Information Division, Defense Manpower Data Center, Seaside, CA. Additionally we thank Michelle Stoia from the Naval Health Research Center. We also thank all the professionals from the US Army Medical Research and Materiel Command, especially those from the Military Operational Medicine Research Program, Fort Detrick, MD. We appreciate the support of the Henry M. Jackson Foundation for the Advancement of Military Medicine, Rockville, $\mathrm{MD}$.

\section{Author details}

${ }^{1}$ Seattle Epidemiologic Research and Information Center, Department of Veterans Affairs Puget Sound Health Care System, Seattle, WA, USA.

${ }^{2}$ Department of Epidemiology, University of Washington, Seattle, WA, USA.

${ }^{3}$ Department of Deployment Health Research, Naval Health Research Center, San Diego, CA. ${ }^{4}$ Analytic Services, Inc. (ANSER), Arlington, VA, USA.

${ }^{5}$ Departments of Preventive Medicine and Biometrics, Uniformed Services University of Health Sciences, Bethesda, MD, USA. ${ }^{6}$ Madigan Army Medical Center, Fort Lewis, WA, USA. 


\section{Authors' contributions}

AJL advised on the approach for statistical analyses and drafted the manuscript. EJB conceived the idea for the study and advised on the approach for statistical analyses. JH and IGJ performed the statistical analyses. All authors participated in the design of the study, edited and revised several drafts, and read and approved the final manuscript.

\section{Competing interests}

The authors declare that they have no competing interests.

Received: 16 March 2010 Accepted: 21 October 2010

Published: 21 October 2010

\section{References}

1. Goldberg M, Chastang JF, Zins M, Niedhammer I, Leclerc A: Health problems were the strongest predictors of attrition during follow-up of the GAZEL cohort. J Clin Epidemiol 2006, 59(11):1213-1221.

2. Young AF, Powers JR, Bell SL: Attrition in longitudinal studies: who do you lose? Aust N Z J Public Health 2006, 30(4):353-361.

3. Cunradi $C B$, Moore R, Killoran M, Ames G: Survey nonresponse bias among young adults: the role of alcohol, tobacco, and drugs. Subst Use Misuse 2005, 40(2):171-185.

4. Tate AR, Jones M, Hull L, Fear NT, Rona R, Wessely S, Hotopf M: How many mailouts? Could attempts to increase the response rate in the Iraq war cohort study be counterproductive? BMC medical research methodology 2007, 7:51

5. Van Beijsterveldt CE, van Boxtel MP, Bosma H, Houx PJ, Buntinx F, Jolles J: Predictors of attrition in a longitudinal cognitive aging study: the Maastricht Aging Study (MAAS). J Clin Epidemiol 2002, 55(3):216-223.

6. Deeg DJ: Attrition in longitudinal population studies: Does it affect the generalizability of the findings? An introduction to the series. J Clin Epidemiol 2002, 55:213-215.

7. Eerola $\mathrm{M}$, Huurre $\mathrm{T}$, Aro $\mathrm{H}$ : The problem of attrition in a Finnish longitudinal survey on depression. Eur J Epidemiol 2005, 20(1):113-120.

8. Kristman VL, Manno M, Cote P: Methods to account for attrition in longitudinal data: do they work? A simulation study. Eur J Epidemiol 2005, 20(8):657-662.

9. Batty GD, Gale CR: Impact of resurvey non-response on the associations between baseline risk factors and cardiovascular disease mortality: prospective cohort study. Journal of epidemiology and community health 2009, 63(11):952-955.

10. Boshuizen HC, Vi Picavet HS, Botterweck A, van Loon AJ, et al: Nonresponse in a survey of cardiovascular risk factors in the Dutch population: determinants and resulting biases. Public Health 2006, 120(4):297-308.

11. Wells TS, Jacobson IG, Smith TC, Spooner CN, Smith B, Reed RJ, Amoroso PJ, Ryan MA, for the Millennium Cohort Study Team: Prior health care utilization as a potential determinant of enrollment in a 21-year prospective study, the Millennium Cohort Study. Eur J Epidemiol 2008, 23(2):79-87.

12. Hooper TI, Gackstetter GD, Leardmann CA, Boyko EJ, Pearse LA, Smith B, Amoroso PJ, Smith TC, Millennium Cohort Study Team FT: Early mortality experience in a large military cohort and a comparison of mortality data sources. Popul Health Metr 2010, 8(1):15.

13. Smith TC, Smith B, Jacobson IG, Corbeil TE, Ryan MA, for the Millennium Cohort Study Team: Reliability of standard health assessment instruments in a large, population-based cohort study. Ann Epidemiol 2007, 17(4):271-284

14. Smith TC, Jacobson IG, Smith B, Hooper TI, Ryan MA, for the Millennium Cohort Study Team: The occupational role of women in military service: validation of occupation and prevalence of exposures in the Millennium Cohort Study. Int J Environ Health Res 2007, 17(4):271-284.

15. Smith B, Wingard DL, Ryan MA, Macera CA, Patterson TL, Slymen DJ, for the Millennium Cohort Study Team: U.S. military deployment during 20012006: comparison of subjective and objective data sources in a large prospective health study. Ann Epidemiol 2007, 17(12):976-982.

16. Smith B, Smith TC, Gray GC, Ryan MA, for the Millennium Cohort Study Team: When epidemiology meets the Internet: Web-based surveys in the Millennium Cohort Study. Am J Epidemiol 2007, 166(11):1345-1354.
17. Smith B, Leard CA, Smith TC, Reed RJ, Ryan MA, for the Millennium Cohort Study Team: Anthrax vaccination in the Millennium Cohort; validation and measures of health. Am J Prev Med 2007, 32(4):347-353.

18. Ryan MA, Smith TC, Smith B, Amoroso P, Boyko EJ, Gray GC, Gackstetter GD, Riddle JR, Wells TS, Gumbs G, et al: Millennium Cohort: enrollment begins a 21-year contribution to understanding the impact of military service. $J$ Clin Epidemiol 2007, 60(2):181-191.

19. Riddle JR, Smith TC, Smith B, Corbeil TE, Engel CC, Wells TS, Hoge CW, Adkins J, Zamorski M, Blazer D: Millennium Cohort: the 2001-2003 baseline prevalence of mental disorders in the U.S. military. I Clin Epidemiol 2007, 60(2):192-201.

20. LeardMann CA, Smith B, Smith TC, Wells TS, Ryan MA, for the Millennium Cohort Study Team: Smallpox vaccination: comparison of self-reported and electronic vaccine records in the Millennium Cohort Study. Hum Vaccin 2007, 3(6):245-251.

21. Dillman D: Mail and internet surveys: the tailored design method New York: Wiley; 2000 .

22. Welch KE, Leardmann CA, Jacobson IG, Speigle SJ, Smith B, Smith TC, Ryan MA: Postcards encourage participant updates. Epidemiology 2009, 20(2):313-314

23. Rao RS, Sigurdson AJ, Doody MM, Graubard BI: An application of a weighting method to adjust for nonresponse in standardized incidence ratio analysis of cohort studies. Ann Epidemiol 2005, 15(2):129-136.

24. Jacobson IG, Smith TC, Smith B, Keel PK, Amoroso PJ, Wells TS, Bathalon GP, Boyko EJ, Ryan MA: Disordered eating and weight changes after deployment: longitudinal assessment of a large US military cohort. American journal of epidemiology 2009, 169(4):415-427.

25. Wells TS, LeardMann CA, Fortuna SO, Smith B, Smith TC, Ryan MA, Boyko EJ, Blazer D: A prospective study of depression following combat deployment in support of the wars in Iraq and Afghanistan. Am J Public Health 2010, 100(1):90-99.

26. Smith TC, Ryan MA, Wingard DL, Slymen DJ, Sallis JF, Kritz-Silverstein D: New onset and persistent symptoms of post-traumatic stress disorder self reported after deployment and combat exposures: prospective population based US military cohort study. Bmj 2008, 336(7640):366-371

27. Etter JF, Perneger TV: Analysis of non-response bias in a mailed health survey. J Clin Epidemiol 1997, 50(10):1123-1128.

28. Eagan TM, Eide GE, Gulsvik A, Bakke PS: Nonresponse in a community cohort study: predictors and consequences for exposure-disease associations. J Clin Epidemiol 2002, 55(8):775-781.

29. Liu H, Cella D, Gershon R, Shen J, Morales LS, Riley W, Hays RD: Representativeness of the Patient-Reported Outcomes Measurement Information System Internet panel. J Clin Epidemiol 2010.

Pre-publication history

The pre-publication history for this paper can be accessed here: http://www.biomedcentral.com/1471-2288/10/99/prepub

doi:10.1186/1471-2288-10-99

Cite this article as: Littman et al: Assessing nonresponse bias at followup in a large prospective cohort of relatively young and mobile military service members. BMC Medical Research Methodology 2010 10:99.

\section{Submit your next manuscript to BioMed Central and take full advantage of:}

- Convenient online submission

- Thorough peer review

- No space constraints or color figure charges

- Immediate publication on acceptance

- Inclusion in PubMed, CAS, Scopus and Google Scholar

- Research which is freely available for redistribution 